\title{
O DIREITO ECONÔMICO COMO FERRAMENTA DE IMPLEMENTAÇÃO DOS DIREITOS HUMANOS NO BRASIL
}

\section{THE ECONOMIC LAW AS A TOOL FOR IMPLEMENTATION OF HUMANS RIGTHS IN BRAZIL}

\author{
Janaína Freiberger Benkedorf Peixer *
}

\begin{abstract}
SUMÁRIO: Introdução. 1. O Direito Econômico como mecanismo de implementação dos Direitos Humanos 2. Os Direitos Humanos e sua relação com a Macrológica do Direito Econômico. Conclusão. Referências
\end{abstract}

RESUMO: O presente estudo investiga à luz da Constituição Brasileira de que forma o Direito Econômico serve como instrumento de concretização de políticas públicas com vistas à implementação dos direitos humanos. Num sistema constitucional em que a dignidade humana é erigida como princípio basilar do sistema jurídico pretende-se analisar de que forma as normas de direito econômico devem ser guiadas pelo legislador a fim de atingirem o bem estar social. Verifica-se que ambas possuem conteúdo aberto e que pretendem fazer justiça não a um caso individual, mas considerando-se o todo em que estão inseridas. O Direito Econômico por meio de suas leis de caráter mutável, de seus institutos e regras, vem a desempenhar papel primordial para a concretização e implementação dos Direitos Humanos no Brasil.

Palavras-chave: Direitos Humanos; Dignidade Humana; Políticas Públicas; Direito Econômico

\begin{abstract}
The present study investigates through the Brazilian Federal Constitution how Economic Rights can be a tool to materialize public politics aiming to implementate Human Rights. In a Constitutional system where human dignity were elevate as a basic principle of the law system, it intends to analyse how Economic law should be guided by policy makers in order to achieve social well being. It verifies that both kind of rights have an open content, as well as they don't intent to make justice to an individual case, but considering all factors where they are inserted. Economic Rights trough its mutable law, its institutes and rules, make an essential role to implementate and materialize Human Rights in Brazil.
\end{abstract}

Key-words: Human Rights; Human Dignity; Public Politics; Economic Rights

\footnotetext{
* Mestranda do curso de Pós-Graduação em Direito na Pontifícia Universidade Católica do Paraná.
} 


\section{INTRODUÇÃO}

O valor da dignidade da pessoa humana é princípio informador da ordem jurídica brasileira, erigido como um dos pilares de sustentação do Estado brasileiro pela Constituição de 1988.

O Brasil reconhece e impõe a elevação do ser humano ao ápice de todo o sistema jurídico. A dignidade da pessoa humana, pois, serve como mola de propulsão da intangibilidade da vida do homem, dela defluindo os direitos e garantias individuais, expressos e implícitos em nosso ordenamento, os direitos sociais e a adoção de políticas públicas visando, além de proteger, promover o ser humano em todas as suas potencialidades.

Para a efetivação destes objetivos o Estado precisa concentrar esforços em busca da concretização de políticas públicas voltadas à promoção do ser humano.

Ao se estudar as normas de proteção dos Direitos Humanos, verifica-se que guardam íntima relação com as normas com as normas de Direito Econômico, que não buscam apenas fazer justiça a um caso, individualmente considerado, mas sim, ao todo em que estão inseridas.

Em uma ordem jurídica em que os Direitos Humanos são colocados como princípios fundamentais e objetivo do Estado, a ideologia constitucionalmente adotada no Brasil aponta na direção de um Estado que proporcione o bem-estar social, oferecendo e respeitando os direitos sociais e individuais, através de uma política econômica que valorize, em primeiro lugar, esses objetivos.

Partindo da análise do tratamento e importância dispensados pelo ordenamento brasileiro às normas de Direitos Humanos, pretende-se analisar de que forma essas normas relacionam-se com a temática do Direito Econômico com vistas à implementação de direitos sociais.

Em suma, visa o presente estudo buscar compreender qual a lógica que sustenta as normas de Direito Econômico nos Direitos Humanos e como essas duas disciplinas se interrelacionam.

\section{O DIREITO ECONÔMICO COMO MECANISMO DE IMPLEMENTAÇÃO DOS DIREITOS HUMANOS}

Os Direitos Humanos são direitos universais atribuídos aos seres humanos exclusivamente em razão da sua dignidade humana e independentemente do reconhecimento formal pelos Estados. Já os Direitos fundamentais são os direitos formalmente reconhecidos pelos 
Estados e assegurados por meio das garantias constitucionais. E para que os direitos fundamentais sejam legítimos é necessário que eles não contrariem os preceitos de direitos humanos, ou seja, é necessário que sejam verdadeiros "direitos humanos fundamentais".

Com o fim da Segunda Guerra Mundial e, em face das atrocidades cometidas pelos nazistas, houve uma tomada de consciência universal, espelhada na Declaração Universal dos Direitos Humanos, tendo como base uma razão jurídica de conteúdo ético, "fundada na garantia da intangibilidade da dignidade da pessoa humana, na aquisição da igualdade entre as pessoas, na busca da efetiva liberdade, na realização da justiça, e na construção de uma consciência que preserve integralmente esses princípios" (NUNES, 2004, p. 361).

A Declaração Universal acabou por fazer uma afirmação solene do valor que é o fundamento da vida social: "a dignidade inerente a todos os membros da família humana". Afirmou-se assim, que as pessoas não são sombras, não são aparências, são realidades concretas e vivas, daí porque a Declaração reconhece que acima das leis emanadas do poder dominante, há uma lei maior de natureza ética e validade universal; e o fundamento dessa lei é o respeito à dignidade da pessoa humana, tendo em vista que a pessoa humana é o valor fundamental da ordem jurídica, sendo, portanto, a fonte das fontes do direito (MONTORO, 1999, p. 28.).

Fruto desta conquista no âmbito da proteção dos direitos humanos surge a consciência universal de que se devia preservar, a qualquer custo, a dignidade da pessoa humana, como uma conquista de valor éticojurídico intangível (NUNES, 2004, p. 368).

Neste sentido explica Flávia Piovesan (2010) que o valor da dignidade da pessoa humana, impõe-se como núcleo básico e informador de todo e qualquer ordenamento jurídico, como critério e parâmetro de valoração a orientar a interpretação e compreensão de qualquer sistema normativo, mormente o sistema constitucional interno de cada país. No âmbito do Direito Constitucional Internacional ocidental são adotados textos constitucionais abertos a princípios, dotados de elevada carga axiológica, com destaque para a dignidade humana.

A primazia jurídica do valor da dignidade humana é resposta à crise sofrida pelo positivismo jurídico, associado ao fascismo e nazismo, que promoveram a barbárie em nome da lei. Nesse contexto, explica a constitucionalista, "ao final da Segunda Guerra Mundial emerge a grande crítica e o repúdio à concepção positivista de um ordenamento jurídico 
indiferente a valores éticos, confinado à ótica meramente formal" (PIOVESAN, 2010, p.28).

A Constituição Brasileira de 1988, chamada de Constituição Cidadã, simboliza o marco jurídico da transição democrática e da institucionalização dos direitos humanos no país. Após vinte e um de regime autoritário, o texto constitucional reflete o consenso democrático "pós-ditadura", objetivando resgatar o Estado de Direito, a separação dos poderes, a Federação, a Democracia e os direitos fundamentais, à luz do princípio da dignidade humana (PIOVESAN; VIEIRA, 2006).

Introduz a Carta de 1988 um avanço extraordinário na consolidação dos direitos e garantias fundamentais. Como observam Piovesan e Viera (2006): "ineditamente, os direitos e garantias individuais são elevados a cláusulas pétreas, passando a compor o núcleo material intangível da Constituição (artigo 60, parágrafo $4^{\circ}$ )”.

Vale destacar que a Constituição de 1988 acolhe a idéia da universalidade dos direitos humanos, na medida em que consagra o valor da dignidade humana, como princípio fundamental do constitucionalismo brasileiro inaugurado em 1988. Ainda, a Constituição Brasileira informa que os direitos humanos são tema de legítimo interesse da comunidade internacional, ao ineditamente prever, dentre os princípios a reger o Brasil nas relações internacionais, o princípio da prevalência dos direitos humanos.

Flávia Piovesan ainda destaca o quão acentuada é a preocupação da Constituição brasileira em assegurar os valores da dignidade e do bem-estar da pessoa humana, como imperativo de justiça social, que os erigiu aos objetivos fundamentais do estado brasileiro, inclusive modificando a topologia constitucional, privilegiando a temática dos direitos fundamentais.

$\mathrm{E}$, para que os direitos humanos sejam plenamente realizados verifica-se que o estado deve garantir condições que possibilitem o desenvolvimento das potencialidades humanas, garantindo a liberdade não só em face ao Estado, mas também face às intervenções de poderes privados.

Segundo Konrad Hesse, os direitos sociais apresentam uma debilidade intrínseca, por não se constituírem como direitos subjetivos, cujo ultraje faz surgir direito de ação contra o Estado, mas direitos "cuja realização depende de 'tarefas do Estado', programas de objetivos sujeitos a amplas margens legislativas e políticas de configuração" (HESSE, 1991, p. 27.). 
E é tendo como espectro este princípio máximo, que as leis - e a tomada de decisão política - devem ser criadas e observadas, buscando concretizar os direitos fundamentais do homem para uma vida com dignidade.

Outrossim, os direitos e garantias individuais têm aplicação imediata. Vale dizer, cabe aos Poderes Públicos conferir máxima e imediata efetividade a todo e qualquer preceito definidor de direito e garantia fundamental, visa tornar tais direitos prerrogrativas diretamente aplicáveis pelos poderes Legislativo, Executivo e Judiciário.

Vale ressaltar que nos termos do artigo $6^{\circ}$ da Constituição de 1988, são reconhecidos como direitos sociais oponíveis ao Estado brasileiro por todos quanto vivam em nosso território: a educação, a saúde, o trabalho, a moradia, o lazer, a segurança, a previdência social, a proteção à maternidade e à infância e a assistência aos desamparados ${ }^{1}$; o que significa dizer que esses direitos retiram do próprio ordenamento os mecanismos de eficácia e a previsão de ações afirmativas para sua realização prática.

Traçando um breve escorço histórico da evolução dos direitos humanos e o papel do estado, José Luiz Quadro de Magalhães (2011) explica que o estado Liberal não intervencionista deixou a miséria social se alastrar, e a sua simples garantia formal das liberdades fundamentais nada representava na prática, uma vez que não existiam meios materiais para que o ser humano pudesse utilizar essa sua liberdade, ou seja: o Estado Liberal pode formalmente garantir a liberdade de consciência, entretanto nunca conseguiu que uma boa parcela da população pudesse realmente usufruir desta liberdade, uma vez que grande parte dessa mesma população não tinha acesso à educação, à informação e à cultura. Esse problema só pôde ser solucionado pelo Estado Social de Direito, no qual os princípios do Socialismo foram somados a princípios do liberalismo político, enquanto o Estado passava também a controlar a economia através de maior ou menor intervenção.

Com os problemas causados pela "concentração capitalista" o Estado moderno criou rotas e caminhos jurídicos para sua função diante desses problemas. Já vimos que após a Primeira Guerra Mundial

\footnotetext{
${ }^{1}$ Sem que essa enumeração seja exaustiva, haja vista o disposto no parágrafo $2^{\circ}$ do artigo $5^{\circ}$ da Constituição Federal que estatui que os direitos e garantias expressos em seu texto não excluem outros decorrentes do regime e dos princípios por ela adotados ou dos tratados internacionais em que a República Federativa do Brasil seja parte.
} 
configurou-se um intervencionismo social baseado na liberdade material e que pôde ser identificado em uma forma conservadora e outra reformista, a primeira voltada para a proteção de certos privilégios e nível de vida de certas classes sociais, enquanto a segunda pretendia levar os benefícios sociais aos grupos menos aquinhoados (SOUZA, 1980, p. 407).

Este é o marco histórico onde se encontram pontos de contato fundamentais do Direito Econômico com os Direitos Humanos.

É a partir do momento em que o Estado passa a intervir na econômica, com um valor superior e diverso do valor encontrado no liberalismo, que apontava somente para o lucro, que se começa a visualizar com clareza a importância das ações estatais intervencionistas para o campo dos Direitos Humanos.

Percebe-se que a intervenção no domínio econômico por parte do Estado pode ser um instrumento eficaz para a concretização dos Direitos Humanos. Por exemplo, quando coíbe atividades nocivas à concorrência, impedindo uma fusão ou incorporação de grandes empresas, quando impede que produtos ou atividades nocivas à saúde e/ ou ao meioambiente sejam comercializados/implementadas.

Logo, o Direito Econômico desempenha importante papel como instrumento de concretização dos direitos e garantias fundamentais para o ser humano, tanto no plano individual, quanto coletivo ao impedir certas práticas e ao incentivar outras (ex.: investimento em saúde e cultura em que as pessoas físicas e especialmente, o empresariado, conseguem deduções no imposto de renda).

O Prof. Washington Peluso Albino de Souza (1983, p. 170) ressalta a íntima relação entre o instituto da intervenção e os direitos sociais fundamentais, componentes dos Direitos Humanos, que já se faziam sentir desde a promulgação da Constituição brasileira de 1934: “Começa por introduzir 'os princípios' da Justiça Social e das necessidades da vida nacional, de que possibilite a todos 'existência digna', ao lado de garantir a 'liberdade econômica dentro de tais limites'. Estes são os elementos fundamentais da 'organização da ordem econômica"".

Pode-se notar, portanto, que a intervenção visa ou deve visar ao bem-estar social, à garantia de direitos sociais e de direitos individuais, e de maneira indireta dos direitos políticos, quando, por exemplo, se evita a concentração econômica dos meios de comunicação social. 
O mesmo autor ainda trata da realidade econômica como objeto do Direito Econômico, ao ressaltar em seus estudos a relação necessária entre o Direito Econômico e os direitos sociais e individuais:

Temos, portanto, a realidade econômica como seu objeto mais próximo e ainda não peculiar. Esta peculiaridade decorre da sua visão mais ampla na participação que recebeu da ação dos indivíduos e do Estado, tomada do ângulo de pretensões mais altas, como seja o desenvolvimento, ou dos interesses mais legítimos por uma qualidade de vida melhor, como a decorrência dos controles dos preços, dos freios jurídicos sobre os efeitos da concentração das empresas, das conseqüências dos monopólios e outras formas de abuso de poder econômico; ou, por outro lado, da garantia de oportunidades de emprego, da política salarial, de mais justa distribuição de renda, do tratamento dos efeitos da política monetária, dos frutos da política de estímulos, de planejamento, e assim por diante (SOUZA, 1983, p.11-12).

O Direito Econômico, através da modificação da realidade econômica, busca melhorar a qualidade de vida da população, com vistas a possibilitar o acesso a todos dos direitos sociais fundamentais que compõem os Direitos Humanos, como: saúde, habitação, lazer, transporte, educação, trabalho etc.

Através de seus mecanismos e regras próprias, o Direito Econômico pode proporcionar os meios (direitos sociais) para que o indivíduo possa realmente ser livre (direitos individuais). Entre estes direitos, pode-se citar o acesso ao trabalho, educação, saúde etc.

Contudo, penosa é a tarefa de concretização dos direitos sociais no plano fático. Krell (2010, p. 51) explica que:

A interpretação dos direitos sociais não é uma questão de lógica, mas de consciência social de um sistema jurídico como um todo, a despeito desse generoso engajamento, forçoso é reconhecer que a efetivação desses direitos não depende da vontade dos juristas, porque, substancialmente, está ligada a fatores de ordem material, de todo alheios à normatividade jurídica, e, portanto, insuscetíveis de se transformarem em coisa por força da palavra. 
Isso significa dizer que estamos condicionados a fatores de ordem material, como o desenvolvimento e disponibilidade de recursos, e pelas decisões políticas fundamentais do estado, pois não são poucos os que ainda afetos à ideologia individualista, mostram-se refratários a qualquer forma de solidarismo social custeado com recursos públicos (MENDES, [et.al] 2010, p. 827).

Observa-se que por um lado os juristas pretendem garantir a máxima efetividade dos direitos humanos, afinal, resulta de um princípio hermenêutico derivado da própria Constituição Federal; de outro, encontram-se cânones interpretativos de igual importância, como da razoabilidade, proporcionalidade, separação de poderes e da reserva do possível, que parecem impedir a total realização desses direitos.

Porém, o Brasil comprometeu-se na esfera interna e internacional a dar primazia à proteção e concretização de políticas públicas voltadas a promoção do ser humano. Ainda que estejamos longe do ideal de concretização de políticas públicas com vistas à máxima efetividade dos direitos e garantias fundamentais do homem, o reconhecimento dos direitos constitui-se no primeiro passo rumo ao ideal de justiça e pacificação social, ou numa fórmula tornada célebre, Hannah Arendt (2000) afirmou que a essência dos direitos humanos é "o direito a ter direitos".

Cabe salientar que é condição para o exercício da democracia a implementação e garantia de direitos fundamentais. E, através de sua lógica própria, o Direito Econômico é campo de atuação e realização dos Direitos Humanos, conforme se verificará na sequência.

\section{OS DIREITOS HUMANOS E SUA RELAÇÃO COM A MACROLÓGICA DO DIREITO ECONÔMICO}

Naturalmente, por ser o Direito uma ciência uma, os ramos, convenções estabelecidas com fins meramente didáticos, interligam-se. Assim, o Direito Administrativo, o Constitucional e outros, tratam de matérias relativas às atividades econômicas existentes. E, portanto, jan a conceituação do Direito Econômico, encontramos importantes pontos de contato com os Direitos Humanos. 
Buscando compreender o objeto de estudo, inicialmente cabe delimitar o campo ou objeto do Direito Econômico, já que é difícil conceituá-lo ${ }^{2}$.

Na tentativa de explicá-lo colhem-se os seguintes ensinamentos:

O Direito Econômico, como ramo autônomo, tem como conteúdo específico de suas normas, as atividades econômicas ocorrentes no mercado, sejam elas provenientes do setor privado ou público. Naturalmente, por ser o Direito uma ciência una, os ramos, convenções estabelecidas com fins meramente didáticos, interligam-se. Assim, o Direito Administrativo, o Direito Constitucional e tantos outros, tratam de matérias relativas às atividades econômicas existentes. No entanto, apenas o Direito Econômico as adota com primazia, considerando a regulamentação destas de modo a torná-las uma política econômica objeto exclusivo seu. Sua finalidade é, dessa forma, regulamentar a atividade econômica do mercado, estabelecendo limites e parâmetros para empresas privadas e públicas. Ele trata de estabelecer uma política econômica no sentido de concretização dos ditames e princípios constitucionais (FDUFMG, ano I, Nov, 1969).

\section{Washington Peluso Albino de Souza (1983) o define como:}

O ramo do Direito, composto por um conjunto de normas de conteúdo econômico e que tem por objeto regulamentar as medidas de política econômica referentes às relações e interesses individuais e coletivos, hamonizando-as - pelo princípio da economicidade - com a ideologia adotada na ordem jurídica.

Portanto, não basta a norma ter um conteúdo econômico para que seja uma norma de Direito Econômico: "O modo de tratar esse conteúdo econômico - aplicando-lhe normas próprias, destacando-lhe regras igualmente próprias e que estejam comprometidas com a regulamentação jurídica da política econômica, condicionando-a aos princípios

\footnotetext{
${ }^{2}$ Explica Roberto Ferraz que muitos já tentaram definir o Direito Econômico, mas o fizeram de forma vaga e indefinida. Champaud, por exemplo, não o definia, mas destacava que tratava-se de um direito original com vocação geral. Somente o espírito era verdadeiramente novo. In Revista de Direito mercantil, 142/80-86.
} 
ideológicos constitucionalmente adotados - este sim, é o seu traço diferencial" (SOUZA, 1983, p. 11).

Roberto Ferraz (2006, p. 80-86) explica que o Direito Econômico não segue o formato dos tradicionais "ramos do Direito", cuja especificidade vem essencialmente da área a que se referem as normas jurídicas, normas estas que seguem a clássica lógica da imputação (ou dos atos formais). Pelo contrário o Direito Econômico não se caracteriza pela matéria de que trata pois trata de concorrência, consumo, direito processual civil, direito tributário, direito administrativo, direito comercial, da regulação, da proteção etc., mas pelo tipo de lógica que dita as normas que se identificam como de direito econômico e que mais e aproxima da lógica de resultados .

Em suma, o que caracteriza as normas de direito econômico não é a matéria, mas sim, o novo enfoque com que foram concebidas: o enfoque macroeconômico.

Continua o jurista explicando que a concepção da norma de direito econômico não visa fazer justiça entre dois indivíduos ou mais; visa fazer justiça num universo de relações conjuntamente considerado, abstraindo das relações individualmente consideradas. A norma de direito econômico visa promover certas tendências macroeconômicas ou dar resposta jurídica a tais tendências. Essas tendências são fatos identificados pelo pensamento macroeconômico (concorrência, repercussão econômica dos custos inclusive tributários, maior eficiência dos agentes de mercado etc.) e, portanto, comportam falhas de análise.

Assim como as normas de direito econômico, algumas normas afetas à concretização de direitos humanos no plano fático, guardam tal particularidade. Ou seja, seguem certas tendências, analisando-se o todo em que estão inseridas e visam fazer justiça à coletividade, e não apenas entre os indivíduos "A" e "B", individualmente considerados.

Ademais, tais escolhas (qual políticas públicas serão implantadas, por exemplo) possuem nítido caráter econômico, visto que as necessidades da população são ilimitadas e os recursos são finitos. Assim, dá-se prioridade a certos aspectos da vida em sociedade, em detrimento de outros.

O Direito, visto sob o prisma de seus ramos tradicionais, era enunciado com vistas à relação jurídica havida entre o titular do direito subjetivo e o titular do dever jurídico correspondente. As causas e as conseqüências próprias de uma relação jurídica eram examinadas de forma intrínseca a esta relação numa lógica própria do primado da 
individualidade. Neste sentido, a lógica de imputação quando da verificação de uma lesão de direito replicava e aplicava a norma do tipo "Se A é B deve ser". Ferraz (2006), tendo por base o Direito Econômico, ensina que aspectos extrínsecos à relação jurídica são relevantes para este ramo, engendrando uma lógica própria e diferenciada. Neste sentir o Direito Econômico traz uma lógica própria e inovadora, que foge àquela vetusta e estruturada pelos demais ramos do Direito, inservíveis, em muitos aspectos, à realidade atual da sociedade. Explica Neves (2011) que:

Revisitar as funções do Estado e restabelecê-las de forma
mais adequada às aspirações da sociedade e do mercado
passa, antes de tudo, pela percepção de que se tratam de
fenômenos reciprocamente interferentes, que têm no Direito
a normatização de suas relações. Tanto, dentro de um
contexto de extrema mutabilidade, contraria antigos e
rígidos preceitos de Direito Público, tais como a soberania,
a insindicabilidade da discricionariedade administrativa, a
intangibilidade dos atos políticos e, até mesmo, o intocável
princípio da supremacia do interesse público.

Sob esta ótica, as normas de Direto Econômico possuem duas especificidades: a) são concebidas menos como comandos direcionados a condutas individuais e mais como fatores que influenciarão macrologicamente as relações de mercado (minimizando os efeitos das falhas); e b) possuem aspecto teleológico na medida em que buscam, pragmaticamente, a realização dos objetivos fixados pelos princípios constitucionais da Ordem Econômica (insculpidos no art. 170 da Constituição de 1988) (EFING; BETTI JUNIOR, 2010).

Neste cenário, encontram-se inúmeras normas que, apesar de não serem propriamente da disciplina de direito econômico, guardam relação com sua lógica, já que escapam à lógica clássica da imputação.

Em relação à norma objeto do presente estudo, verificam-se inúmeras possibilidades na Lei para que o governo brasileiro, por meio de seus agentes, realizem ou não políticas públicas com vistas a melhorar a qualidade de vida dos brasileiros e realizar os direitos humanos no plano concreto. Trata-se, pois, de uma decisão política de caráter discricionário.

O Direito Econômico busca harmonizar as medidas de política econômica públicas e privadas, através do princípio da economicidade, 
com a ideologia constitucionalmente adotada. Segundo Peluso é "o ramo do Direito que tem por objeto a regulamentação da política econômica e por sujeito o agente que dela participe. Como tal, é um conjunto de normas de conteúdo econômico que assegura a defesa e harmonia dos interesses individuais e coletivos, de acordo com a ideologia adotada na ordem jurídica" (1977, p.23).

$\mathrm{Na}$ presente Constituição, os elementos componentes da atual ideologia encontram-se, em sua maior parte, reunidos em seu Título VIII, da Ordem Econômica e Financeira, embora haja disposições esparsas em outras partes do texto constitucional.

José Luiz Quadros de Magalhães (2011) destaca que esse ramo do Direito regulamenta juridicamente a política econômica que deve estar sujeita à ideologia constitucionalmente adotada; portanto, em uma Constituição que, como a de 1988, estabelece como princípios fundamentais o respeito à dignidade humana, a erradicação da pobreza, a redução das desigualdades sociais e regionais, a prevalência dos Direitos Humanos, o Direito Econômico se transforma em importante e fundamental mecanismo de transformação da realidade econômica e social, através de uma política econômica adequada aos princípios constitucionais citados.

Por assumir como tema a ideologia constitucional adotada, assunto suscetível de contínuas modificações, o emprego deste princípio vem a corresponder à necessidade de flexibilidade das normas de Direito Econômico face às diversas circunstâncias com que este se depara, ao longo da trajetória econômica de um país. Um mesmo fato em contextos distintos pode levar a decisões inteiramente contrárias, sem a ocorrência de qualquer contradição. Trata-se de simples ajuste ao dispositivo constitucional adequado para situações individualizadas, realizado pelo instrumento harmonizador da economicidade (SOUZA, 1977, p. 28-29).

Explica Cláudia Maria Toledo Silveira (1997) que essa 'maior vantagem' há de ser adequada aos objetivos constitucionalmente definidos. Permite, destarte, a opção mais justa ou recomendável, em política econômica, a ser realizada pelo aplicador ou intérprete da norma, quando da realização concreta de situações hipoteticamente previstas. $\mathrm{O}$ ideal é que se consiga conciliar aquilo tomado como certo economicamente, com o considerado justo juridicamente. Em caso de incompatibilidade, deve prevalecer o justo. Afinal a linha de maior vantagem' é pautada em temos do 'valor justiça'. Restringe-se o arbítrio, o poder de decidir do aplicador, o qual se deve ater às disposições 
constitucionais e princípios hermenêuticos, preterindo-se qualquer subjetividade (SOUZA, 1992, p. 35).

Muitas vezes, a solução mais vantajosa para a situação não se trata daquela mais lucrativa em termos financeiros. Tudo dependerá da finalidade que se busca atingir. Se se almeja, por exemplo, o alcance da instalação telefônica em meios rurais de difícil acesso, apesar de ser uma obra extremamente dispendiosa e de pouco retorno financeiro, em se concretizando tal meta, o objetivo social terá sido realizado, embora não sejam auferidos lucros em matéria de rendas e sim de benefícios para a população.

Notória é a adoção, pela atual Constituição brasileira, da garantia do exercício dos direitos sociais e individuais como valores supremos; da cidadania e da dignidade da pessoa humana como fundamentos; da construção de uma sociedade livre, justa e solidária, bem como da erradicação da pobreza e redução das desigualdades sociais e regionais como objetivos fundamentais e, finalmente, da prevalência dos Direitos Humanos como princípio.

Dessa maneira, o Direito Econômico funciona como instrumento para que tais metas sejam alcançadas e cumpridas, visto que, é somente através dele, com suas normas, regras, institutos e características próprios que se pode fazer uma regulamentação jurídica da política econômica a ser adotada para que se concretize a ideologia assumida pela Constituição.

\section{CONCLUSÃO}

Ao erigir entre os objetivos do Estado a dignidade e o bem-estar da pessoa humana como imperativo de justiça social, o Brasil comprometeu-se perante a ordem interna e internacional com a efetivação e primazia dos direitos humanos, através de políticas públicas e respeito ao ser humano.

A Constituição brasileira de 1988 estabelece que a política econômica deve-se pautar por conferir prioridade aos Direitos Humanos, ao se reduzirem as desigualdades sociais, ao implementar ou, em vários casos, construir a cidadania, dentro outros, dispostos no preâmbulo e nos artigos $1^{\circ}$ a $4^{\circ}$. No texto constitucional, depreende-se que o valor constante em suas disposições é a primazia pelo ser humano, tornando-se este, então, o objetivo de qualquer medida de política econômica, a despeito do lucro exclusivamente material. 
Desse modo, o Direito Econômico funciona como meio através do qual se torna possível a concretização dos direitos sociais. Somente a partir da existência destes, é que se pode chegar à efetivação dos direitos individuais e à plena realização dos Direitos Humanos.

Evidencia-se o fato de que os Direitos Humanos formam um corpo uno, de forma que, se lhe falta algum de seus componentes, como os direitos sociais, por exemplo, os direitos individuais não se realizam, não conseguindo, o indivíduo, desfrutar de uma vida digna.

A relação existente entre a realização dos objetivos do Estado, a concretização dos direitos individuais e sociais, previstos na Constituição Federal com as normas de direito econômico, pelo viés macrológico, é que todas essas são percebidas em um contexto maior, analisando-se a conjuntura econômica, social, política do país em um determinado momento histórico (condições subjetivas) e não apenas o caso atendendo a interesses individuais (relação entre sujeitos determinados, A e B).

Tratam-se de normas de conteúdo aberto e que têm como pano de fundo uma análise social, decisão política, pessoal e econômica, que vão além da análise meramente impositiva, lógica e formal de uma norma jurídica tradicional.

O Direito Econômico, portanto, por meio de suas leis de caráter mutável, de seus institutos e regras, vem a desempenhar papel primordial para a concretização e implementação dos Direitos Humanos no Brasil.

Pretendeu-se demonstrar neste estudo a forma interrelacional que esses dois ramos do direito trabalham para consecução de objetivos afins, e que a lógica que sustenta as normas de direito econômico no ramo dos direitos humanos é a busca pela garantia constitucional da dignidade humana.

\section{REFERÊNCIAS}

ARENDT, Hannah. A condição humana. 9. ed. Rio de Janeiro: Forense Universitária, 2000.

Dicionário de Direito Econômico. Cadernos de Direito Econômico. FDUFMG, ano I, Nov. 1969.

EFING, Antonio Carlos; BETTI JUNIOR, Leonel Vinícius Jaeger Direito Econômico E Modernidade: a Função Socioambiental e e Resignificação Reflexiva do Direito à Informação para o Consumo. 
Disponível em: 〈http://www.conpedi.org.br/anais/36/02_1448.pdf〉 Acesso em 30 de maio de 2011.

FERRAZ, Roberto. A macrológica do direito econômico. In Revista de Direito mercantil, 142/80-86, 2006.

HESSE, K. A Força Normativa da Constituição. Tradução de Gilmar Ferreira Mendes. Porto Alegre: Sérgio Antônio Fabris, 1991.

MAGALHAES, José Luiz Quadros de. Direito Econômico e Direitos Humanos. Disponível em:

$<$ http://joseluizquadrosdemagalhaes.blogspot.com/2011/05/357-direitoshumanos-36-direito.html> Acesso em 07 de jun. de 2011

MENDES, Gilmar F.(Et al). Curso de Direito Constitucional. $5^{\mathrm{a}}$. ed. São Paulo: Saraiva, 2010.

MONTORO, André Franco. Cultura dos direitos humanos in Direitos Humanos: legislação e jurisprudência (Série Estudos, n. ${ }^{\circ} 12$ ), Volume I. São Paulo: Centro de Estudos da Procuradoria Geral do Estado, 1999.

NEVES, Sérgio Barbosa. Direito Econômico a sua nova lógica para o direito administrativo: as agências reguladoras. Revista da PGE/RJ n. 64, 2011. Disponível em: < http://download.rj.gov.br/documentos/10112/312688/DLFE28578.pdf/18DireitoEconomico esuanovalogica.pdf > Acesso em 30 de maio de 2011.

NUNES, Luiz Antonio Rizzatto. Manual de filosofia do direito. São Paulo: Saraiva, 2004.

\section{PIOVESAN, Flávia. Direitos Humanos e o Direito Constitucional} Internacional, $11^{a}$ ed. São Paulo: Saraiva, 2010.

PIOVESAN, F.; VIEIRA, R. S. Justiciabilidade dos Direitos Sociais e Econômicos no Brasil: desafios e perspectivas. Revista Iberoamericana de Filosofía, Política y Humanidades. Año 8, No 15: Primeiro semestre de 2006. ISSN 1575-6823. Disponível em: 〈http://us.es/araucaria> Acesso em 04 de abril de 2111. 
SILVEIRA, Cláudia Maria Toledo. Direito Econômico e Cidadania. Jus Navigandi, Teresina, ano 2, n. 20, 12 out. 1997. Disponível em: <http://jus.uol.com.br/revista/texto/80>. Acesso em: 6 jun. 2011.

SOUZA, Washington Peluso Albino de. Direito econômico. São Paulo: Saraiva, 1980. . O discurso intervencionista nas Constituições brasileiras.

Cadernos de Direito Econômico, São Paulo, n. 1, p. 170, 1983. . Primeiras linhas de direito econômico. Belo Horizonte:

Fundação Brasileira de Direito Econômico, 1977. . Conflitos ideológicos na constituição econômica. Revista

Brasileira de Estudos Políticos. Belo Horizonte, nº 74/75, 1992. 